\title{
Asynchronous electric drive with an additional switch in the DC link of the frequency converter
}

\author{
D. Yu. Kukishev ${ }^{1}$, V. N. Meshcheryakov ${ }^{1}, V . N$. Voyekov $^{1}$, and I.V. Ivshin ${ }^{2}$ \\ ${ }^{1}$ LSTU, Department of Electric Drive, 398055 Lipetsk, Russia \\ ${ }^{2}$ The department "power supply of industrial enterprises", Kazan State Power Engineering University, Kazan, Russia
}

\begin{abstract}
Regulation of power on an inverter entrance - one of key tasks in the modern electric drive. In this article the way of regulation of power on an inverter entrance by means of the additional switchboard in a link of a direct current for the electric drive on the basis of the asynchronous engine with a short-circuited rotor (ADKZ) with vector management, with relay management of transistor keys of AIT was considered. Comparison of frequency of switching of keys of the inverter is carried out, at various levels of restriction of current in a link of a direct current.
\end{abstract}

\section{Introduction}

Thanks to development of the microprocessor equipment and power electronics introduction of frequency electric drives for such mechanisms as fans, pumps, for the purpose of increase in efficiency of the electric drive, namely energy saving became possible. Achievement of this purpose is possible in two ways: 1. Introduction on production of highly effective electric motors.2. Introduction on production of semiconductor converters of frequency, with the improved power characteristics. Various types of the frequency converters (FC), but are known today, strong development of element base of power electronics promotes the increasing application of $\mathrm{PCh}$ constructed on the basis of completely operated IGBT transistors which have high switching ability. Thanks to new control algorithms of power keys of the converter of frequency, the solution of a problem of regulation of power on an inverter entrance became possible. The set of works is devoted to this problem [1][2][3][4]. Analyzing already available works, it is possible to draw a conclusion that in most cases, for control of the additional switchboard in a link of a direct current, the method of the pulse-width modulation (PWM) is offered. But also other way - relay management is possible.

The electric drive about ADKZ [5] operated by a vector control system with relay management of transistor keys of AIT is taken as a basis of a research. As the additional switchboard in a link of a direct current the IGBT transistor is taken. AIT is connected to the power supply, in our case - to the uncontrollable rectifier [6].

The function chart of system of vector management of the asynchronous electric drive is submitted in the figure 1 . The power scheme of the asynchronous electric drive with the additional switchboard in a link of a direct current is submitted in the figure 2 .

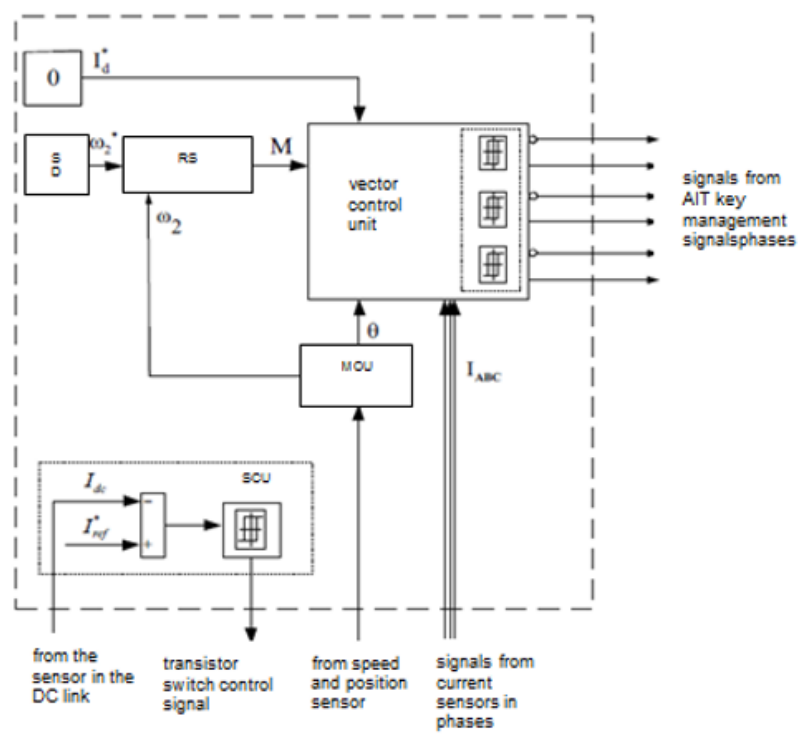

Fig. 1. The function chart of system of vector management of the asynchronous electric drive with the switchboard in a link of a direct current.

The power scheme of a link of a direct current [7] is submitted in the figure 3 . In an algorithm of work of this scheme two states stand out clearly. The first state - the VT transistor is switched on, the source of constant tension is connected to loading through a throttle of $\mathrm{L}$. At the same time the throttle of $\mathrm{L}$ and the condenser $\mathrm{C}$ accumulate energy from a source which is also spent on $\mathrm{R}$ loading. The equivalent circuit for this interval is submitted in the figure 4 . 


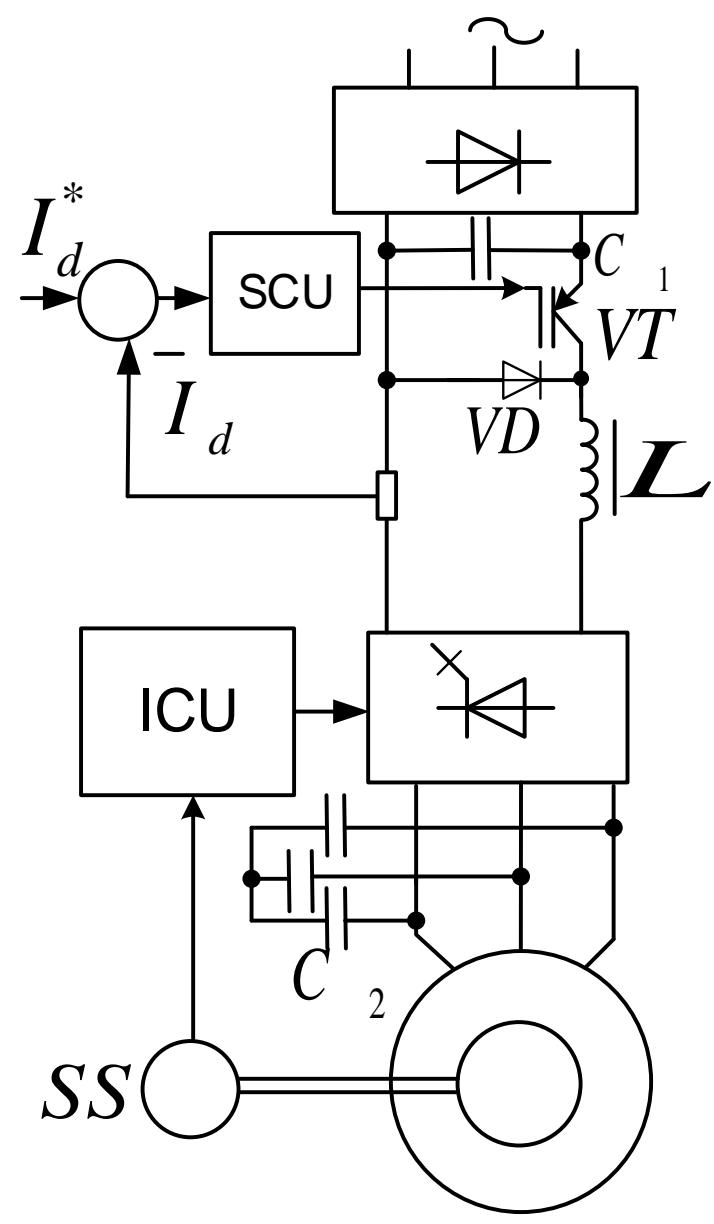

Fig. 2. The power scheme of the asynchronous electric drive with the additional switchboard in a link of a direct current.

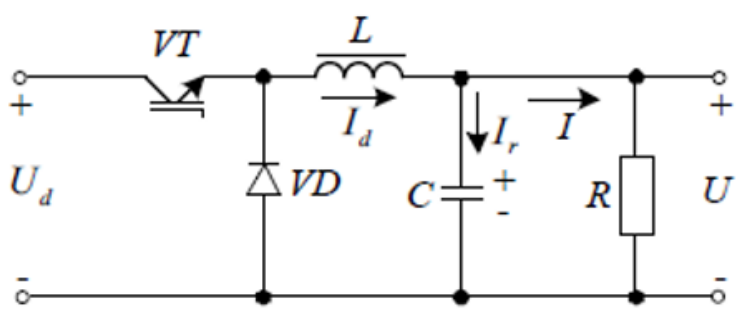

Fig. 3. Power scheme of a link of a direct current.

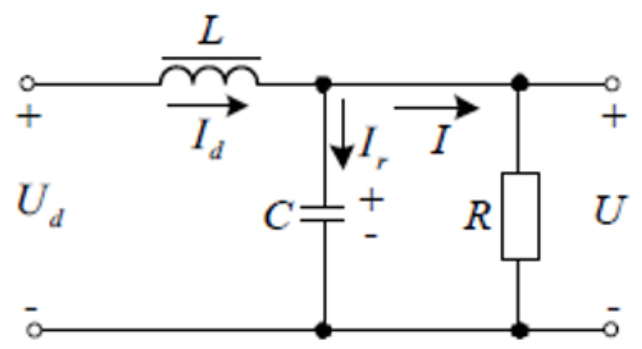

Fig. 4. The equivalent circuit in the first state.

The second state - the VT transistor is switched off and current from a throttle of $\mathrm{L}$ becomes isolated via the diode shown in the figure 3.18 and also current of the condenser proceed on tension converter exit in $\mathrm{R}$ loading $[8,9]$. The equivalent circuit for the second state is submitted in the figure 5 .

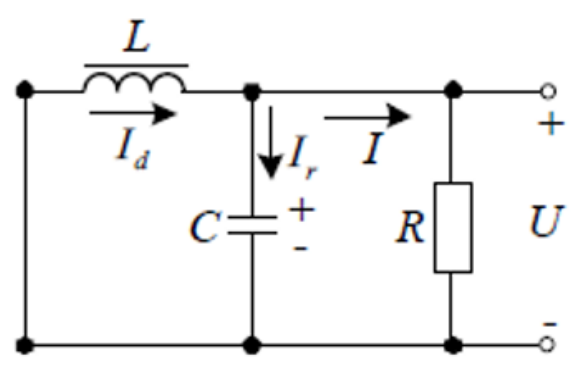

Fig. 5. The equivalent circuit in the second state.

The operated switchboard in a link of a direct current receives a task from the hysteresis regulator which is built in the control unit of the switchboard, and the frequency of switching of the operated VT switchboard depends on hysteresis module width $[10,11]$. The function chart of the control unit of the switchboard is submitted in the figure 6 . Regulation happens by comparison of a preset value on an entrance to the measured value. In case of relay regulation of current the task for maintenance of a certain value of current of $I_{d}$ * = by const in a link of a direct current is used. The key of VT becomes isolated when the difference between the set $I_{d} *$ and the actual current of $I_{d c}$ of a link of a direct current reaches the lower threshold of operation of the module of a hysteresis. The key is disconnected at the moment when the difference reaches the top threshold of turning on of the module of a hysteresis $[12,13]$. Thanks to it level current is stabilized about set.

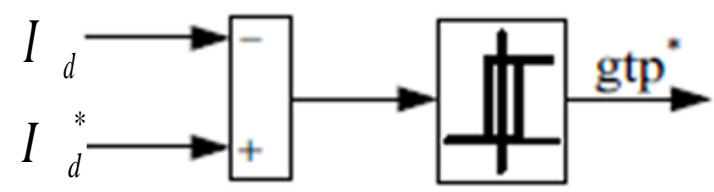

Fig. 6. Function chart of the control unit of the switchboard.

In the figure 7 the model, the asynchronous electric drive with the additional switchboard in a link of a direct current, in the environment of Matlab is shown, at management with maintenance of a constant task for $\mathrm{I}_{\mathrm{d}} *=1870 \mathrm{~A}$ current at dispersal and $1970 \mathrm{~A}$ at the established speed. Feedback comes to the relay regulator from the current measuring instrument. Hysteresis module width for the relay regulator in a link of a direct current is chosen equal 1A. Results of modeling are given in figures 8-10.

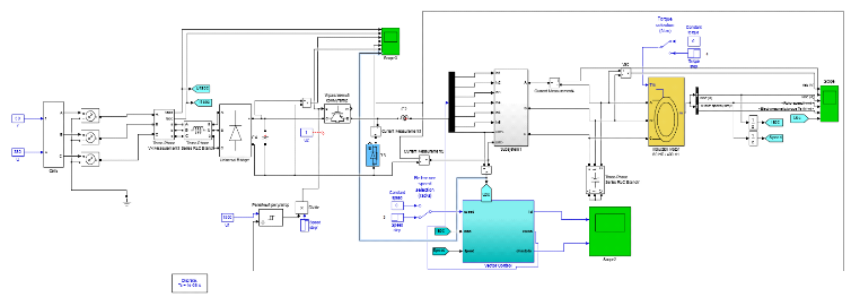

Fig. 7. Model of vector control of the asynchronous electric drive. 


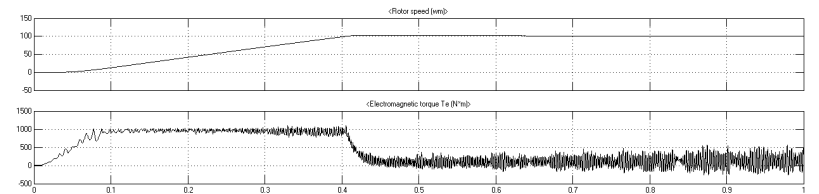

Fig. 8. Schedules of change: a) speed; b) torque.

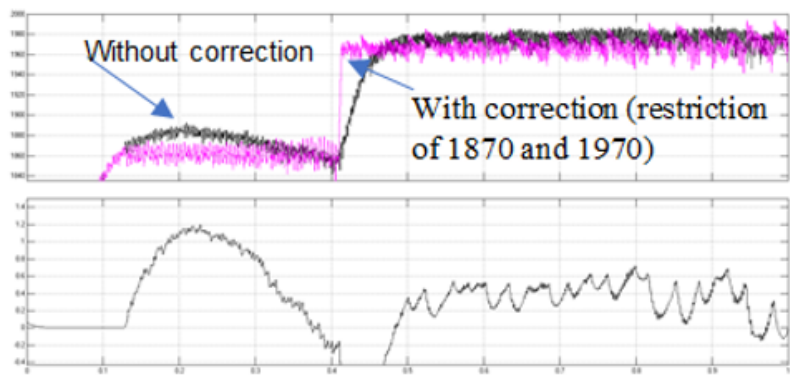

Fig. 9. Schedules of change: a) current of a link of constant tension; b) reduction of frequency of switching of keys of the inverter in $\%$.

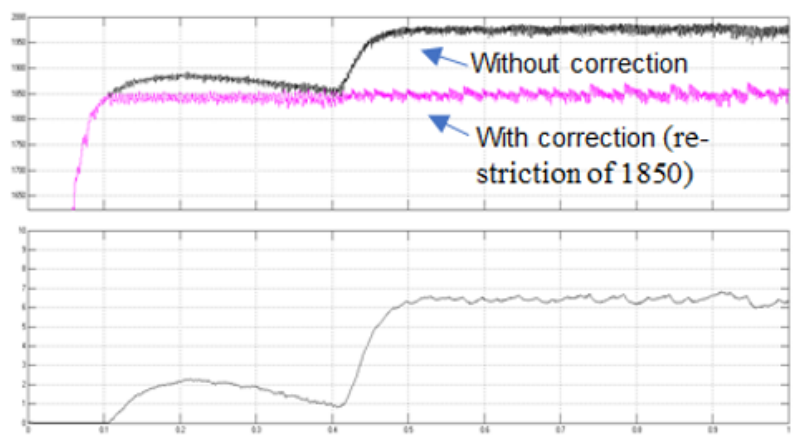

Fig. 10. Schedules of change: a) current of a link of constant tension; b) reduction of frequency of switching of keys of the inverter in \%.

Analyzing the schedules submitted in figures 9, 10 it is possible to draw a conclusion that, holding current in a link of a direct current at the set level, by means of the additional switchboard, we resolve not only an issue of regulation of power on an inverter entrance, but also we regulate the frequency of switching of keys of the inverter. The less we keep current in a link of a direct current, the less frequency of switching.

\section{Acknowledgements}

Article is written with assistance of a grant of the Russian Federal Property Fund 19-48-480001 "Development, a research and optimization of the energy saving electrotechnical and electrodriving automated complexes for plasma, electrometalslag and induction technologies and units".

\section{References}

[1] V.Yu. Alekperov, R.U. Maganov, V.F. Forest warden, V.I. Grayfer, A.V. Bezzubov, N.P. Khokhlov, M.Ya. Ginzburg, V.I. Pavlenko, V.I. Sagalovsky, A.V. Sagalovsky, V.M. Volkov, G.L. Agapova, The Applicant and the patent holder Open joint-stock company The Lukoil oil company, Open joint-stock society Russian Innovation Fuel and Energy Company, Patent no. 2207700, Way of control of the valve electric motor, no. 2000108696/09, zayavl. 11.04.2000, opubl. 27.06.2003

[2] Yu.S. Usynin, Control systems of electric drives: studies. grant (Chelyabinsk: Publishing house YUURGU, 358, 2001)

[3] B.L. Aliyevsky, S.A. Scherbakov, S.R. Mizyurin, The valve generator for the autonomous systems of power supply of a direct current, Electricity, 1, 27-32 (2003)

[4] V.N. Meshcheryakov, V.N. Voyekov, A vector control system of the valve electric drive on the basis of the independent inverter of tension with relay regulation of entrance current of the inverter and phase currents of the stator, Messenger YUURGU, Power series 17, 2, 48-57 (2017)

[5] V.N. Meshcheryakov, P.E. Tsvetkov, Sistema of the optimum frequency asynchronous electric drive with correction on a longitudinal component of current of the stator, News of higher education institutions, Electromecanics, 3, 36-39 (2012)

[6] Y.I. Gracheva, O.V. Naumov, Operating Mode Influence on Probability Characteristics of Electric Devices, Journal of engineering and applied sciences 11, 1, 2934-2938 (2016)

[7] Y.I. Gracheva, N.V. Chernova, A.I. Fedotov, E.A. Fedotov, Local Fourier transformation application for mathematic modeling of synchronous machine valve actuator, Journal of engineering and applied sciences 11, 1, 29392945 (2016)

[8] V.N. Voyekov, V.N. Meshcheryakov, Relay regulation in the frequency converter with the independent inverter of current, Electrical equipment: network online scientific magazine $\mathbf{2}$, 2, 30-34 (2015)

[9] A.S. Anuchin, Control systems of electric drives: textbook for higher education institutions (M.: MEI publishing house, 373, 2015)

[10] V.N. Meshcheryakov, V. Voyekov, Patent holder federal state-funded educational institution of higher education of Lipetsk State Technical University, Patent no. 166655, The device for control of the electric drive of alternating current (LSTU) (RU), Bull. 34, no. 2016113199/07, zayavl. 06.04.2016, opubl. 10.12.2016

[11] Yu.N. Kalachev, Vector regulation (practician's note); methodical instructions (M.: EFO, 63, 2013)

[12] S.G. Herman-Galkin, Virtual laboratories of semiconductor systems in the environment of Matlab-Simulink: textbook (SPb.: Lan publishing house, 448, 2013)

[13] L. Ting, Y. Tan, G.Wu, W. Shumao, Simulation of PMSM vector control system based on matlab, Simulink. Proc. IEEE Int. Conf. Measuring Technology and Mechatronics Automation (ICMTMA09) 2, 343-346 (2009) 